Fetal Diagnosis and Therapy
Fetal Diagn Ther 2010;27:1-7

DOI: $\underline{10.1159 / 000271995}$
Received: November 2, 2009

Accepted after revision: November 13, 2009

Published online: December 24, 2009

\title{
Update on Procedure-Related Risks for Prenatal Diagnosis Techniques
}

\author{
Ann Tabor ${ }^{a}$ Zarko Alfirevic ${ }^{b}$ \\ ${ }^{a}$ Department of Fetal Medicine, Copenhagen University Hospital Rigshospitalet and Faculty of Health Sciences, \\ Copenhagen, Denmark; ${ }^{b}$ Division of Perinatal and Reproductive Medicine, University of Liverpool, \\ Liverpool Women's Hospital, Liverpool, UK
}

\section{Key Words}

Amniocentesis • Chorionic villus sampling • Fetal loss •

Prenatal diagnosis

\begin{abstract}
Introduction: As a consequence of the introduction of effective screening methods, the number of invasive prenatal diagnostic procedures is steadily declining. The aim of this review is to summarize the risks related to these procedures. Material and Methods: Review of the literature. Results: Data from randomised controlled trials as well as from systematic reviews and a large national registry study are consistent with a procedure-related miscarriage rate of $0.5-1.0 \%$ for amniocentesis as well as for chorionic villus sampling (CVS). In single-center studies performance may be remarkably good due to very skilled operators, but these figures cannot be used for general counselling. Amniocentesis performed prior to 15 weeks had a significantly higher miscarriage rate than CVS and mid-trimester amniocentesis, and also increased the risk of talipes equinovarus. Amniocentesis should therefore not be performed before $15+0$ weeks' gestation. CVS on the other hand should not be performed before 10 weeks' gestation due to a possible increase in risk of limb reduction defects. Discussion: Experienced operators
\end{abstract}

\section{KARGER}

Fax +4161306 1234

E-Mail karger@karger.ch

www.karger.com
C) 2009 S. Karger AG, Basel

$1015-3837 / 10 / 0271-0001 \$ 26.00 / 0$

Accessible online at:

www.karger.com/fdt have a higher success rate and a lower complication rate. The decreasing number of prenatal invasive procedures calls for quality assurance and monitoring of operators' performance.

Copyright $\odot 2009$ S. Karger AG, Basel

\section{Introduction}

It is now more than 40 years since amniocentesis was introduced as a diagnostic invasive procedure in the second trimester of pregnancy [1]. The results tend to be available after 16 weeks of gestation, making termination of pregnancy, in case of an abnormal result, very stressful. Chorionic villus sampling (CVS) was developed as a first trimester alternative.

Traditionally, the indications for both tests have been very similar, with advanced maternal age being the principal one. In some European countries more than $10 \%$ of the pregnant population undergoes invasive prenatal testing [2]. However, the combination of ultrasound and biochemical markers has changed the paradigm of antenatal screening for Down's syndrome.

The proportion of pregnant women having an invasive test has been steadily declining [3] with the shift towards 
earlier testing. The risk assessment may be available as early as 10 weeks of gestation underlining the importance of safe early invasive tests.

The aim of this review is to summarize the risks related to invasive procedures.

\section{How to Choose?}

\section{Indications}

Advanced maternal age, usually defined as 35 years or more, used to be the most common indication for invasive prenatal diagnosis. In many countries, this indication has been replaced by an individualised risk assessment for Down's syndrome based on maternal age, gestational age, and a combination of ultrasonic and biochemical markers. Maternal age performed poorly as a selection criterion for invasive diagnostic testing as only about $30 \%$ of Down's syndrome fetuses were detected by offering amniocentesis or CVS to $10 \%$ or more of the pregnant population.

Much more selective individualised risk assessment requires a set-up capable of offering screening to all pregnant women with an invasive procedure being offered when the estimated risk is above a certain cut-off. The policy established by the Fetal Medicine Foundation used a risk of having a Down's syndrome fetus of 1 in 300 at the time of testing as a cut-off [4]. Countries like Denmark have adopted this policy successfully [3].

First trimester risk assessment using the double test (pregnancy-associated plasma protein A (PAPP-A) and free beta-human chorionic gonadotropin $(\beta-\mathrm{HcG})$ ) and nuchal translucency thickness in combination with maternal age has been shown to be very efficient giving a detection rate of 90 for a 5\% false-positive rate [4]. It has been possible to incorporate this policy at a national level, while maintaining detection and false-positive rates [3]. Risk assessment is continuously evolving and new markers, such as nasal bone, ductus venosus, tricuspid regurgitation, placental growth factor, are investigated and may be incorporated into the screening algorithm $[4,5]$.

Other indications include a previous pregnancy with a chromosomal abnormality, a parent with a chromosomal abnormality or carrier of an autosomal-recessive disorder, and identification of a structural fetal abnormality by ultrasound.

In multiple pregnancies, the risk of having at least one fetus with a chromosome abnormality is higher than in singleton pregnancies of the same maternal age. Before undergoing invasive testing, the pregnant woman and her partner should be informed about the option of selective termination. Data from a large collaborative study including 345 selective terminations in twins showed that the miscarriage rate of the whole pregnancy before 24 weeks was 7.0\% [6]. Selective terminations before 15 weeks seemed associated with a lower risk than if the procedure were performed later in pregnancy. This speaks in favour of opting for CVS as the invasive procedure of choice in twin pregnancies.

\section{Risks}

Pregnancy Loss/Miscarriage

Maternal risks are small and extremely rare, therefore only fetal risks will be addressed in this paper.

The total pregnancy loss after invasive prenatal diagnostic procedures consists of a procedure-related loss, which should be added to the background loss rates. The spontaneous fetal loss rate has been difficult to estimate, as large populations have not been followed from early pregnancy. Previously published attempts to ascertain spontaneous fetal losses may have been biased because of different definitions of fetal loss and length of follow-up, different methods to confirm a pregnancy's viability and different intervals between the ultrasound scan showing a live fetus and fetal demise [7].

The background loss rate in women in whom invasive testing may be indicated is related to maternal age, gestational age and the indication for the procedure. The risk will therefore be different for units serving a defined population from those working as a referral centre serving a high-risk population. The background loss rate thus depends on the case mix of the unit.

In a randomised trial, comparing amniocentesis with ultrasonography only in the control group the procedurerelated fetal loss of amniocentesis performed at a mean gestational age of 16 weeks was estimated to be $1.0 \%$ (95\% confidence interval (CI) $0.3-1.5 \%$ )[8]. To be ethically acceptable, this study was performed only in women aged 25-34 years, who would not otherwise have been offered an invasive procedure. A number of more recently published case-control or uncontrolled studies in women at increased risk for Down's syndrome did not show an increased risk of abortion associated with second trimester amniocentesis, but those studies often lacked sufficient power to identify small differences [9-11]. The very low procedure-related risk of 1 in 1,600 attributable to amniocentesis suggested by the FASTER trial [12] may be due to the use of a nonrandomized control group, a source of considerable bias [13]. 
Table 1. Rate of amniotic fluid leakage and rate of talipes in the infants according to gestational age at amniocentesis

\begin{tabular}{llll}
\hline Study & $\begin{array}{l}\text { Gestational } \\
\text { age at amnio- } \\
\text { centesis, weeks }\end{array}$ & $\begin{array}{l}\text { Rate of am- } \\
\text { niotic fluid } \\
\text { leakage, \% }\end{array}$ & $\begin{array}{l}\text { Rate of tali- } \\
\text { pes in the } \\
\text { infants, \% }\end{array}$ \\
\hline Tabor et al., 1986 [8] & 16 & 1.7 & 0.8 \\
Smidt-Jensen et al., 1992 [30] 15 & 2.8 & 0.5 \\
CEMAT, 1998 [19] & 15 & 2.4 & 0.2 \\
Philip et al., 2004 [29] & 14 & 9.7 & 0.9 \\
CEMAT, 1998 [19] & 12 & 4.6 & 1.3 \\
Sundberg, 1997 [28] & 12 & 4.4 & 1.7 \\
\hline
\end{tabular}

The fetal loss rate following CVS has not been compared with no invasive testing in randomised studies, but was found to be comparable to the fetal loss rate after amniocentesis [14-16]. A Cochrane review of amniocentesis and CVS concluded that the total pregnancy loss of transabdominal CVS is comparable to that of second-trimester amniocentesis (OR 0.90, 95\% CI, 0.66-1.23), while transcervical CVS is likely to be associated with a significantly higher risk of miscarriage (OR 1.40, 95\% CI, 1.091.81) [17].

Early amniocentesis, defined as amniocentesis performed between 9 and 14 weeks, on the other hand was shown to carry a significantly higher risk of fetal loss than either CVS or amniocentesis performed in week 16 or later $[18,19]$.

The most recent systematic review of the procedurerelated complications of amniocentesis and CVS included 29 observational studies published after 1995 on amniocentesis and 16 studies on CVS [13]. Pregnancy loss before 24 weeks was $0.9 \%$ following amniocentesis and $1.3 \%$ following CVS with a wide variation between studies.

In the randomised trial of amniocentesis, the control group had a $0.7 \%$ rate of fetal loss from week 16 [8], and the same rate was found in a French study of 3,472 women having amniocentesis compared to 47,004 controls [20]. The spontaneous miscarriage rate is higher following CVS than following amniocentesis, given that CVS is performed at around 12 weeks of gestation and amniocentesis at 16 weeks. Therefore the estimated pregnancy loss rates from the systematic review [13] suggest that the procedure-related loss rate may be lower than the $1 \%$ found in the randomised trials.

In a Danish national register-based cohort study, the post-procedural fetal loss rate, i.e. miscarriage rate before 24 weeks, was assessed among singleton pregnant women

Risks of Invasive Procedures who had an amniocentesis ( $\mathrm{n}=32,852)$ or CVS ( $\mathrm{n}=$ 31,355) between 1996 and 2006 [21]. The miscarriage rate after amniocentesis was $1.4 \%$ (95\% CI 1.3-1.5) and $1.9 \%$ (95\% CI 1.7-2.0) after CVS.

It may thus be concluded that data from randomised controlled trials as well as from systematic reviews and a large national registry study are consistent with a procedure-related miscarriage rate of $0.5-1.0 \%$ for amniocentesis as well as for CVS. In single-center studies performance may be remarkably good due to very skilled operators [10,22], but these figures cannot be used for general counselling.

\section{Multiple Pregnancies}

The background rate of spontaneous loss is higher in twin pregnancies than in singletons, and is associated with chorionicity [23]. No randomised study has been performed in twin pregnancies to assess the miscarriage rate associated with an invasive procedure, and the published series are small. Several cohort studies have compared post-procedure miscarriage rate in twin pregnancies having an amniocentesis or CVS with that in twin pregnancies without invasive procedure or singletons with an invasive procedure [24-26]. The attributable risk of pregnancy loss was significantly greater in twin pregnancies after amniocentesis (2.7\%), compared with nonamniocentesis twin pregnancies $(0.6 \%)$ and post-amniocentesis singletons $(0.6 \%)$ [25]. It should be noted that the risk in the two control groups was lower than expected. A very similar estimate was, however, reported by Cahill et al. [24] in a series of 311 amniocenteses in twin pregnancies. A meta-analysis of 2,026 women with twin pregnancies having amniocentesis concluded that the risk of fetal loss was significantly increased, with an OR of 2.42 (95\% CI 1.24-4.74) [27].

The overall rate of pregnancy loss in twin pregnancies following CVS was comparable to that of amniocentesis (3.2\% for CVS and 2.9\% for amniocentesis [26]). An increased risk of losing at least one fetus was, however, found in the amniocentesis group (9.3 vs. $4.9 \%$ ).

It may be concluded that in twin pregnancies, the rate of fetal loss following amniocentesis or CVS was higher than in singleton pregnancies. It is still uncertain if this is due to the higher spontaneous fetal loss rate in multiple pregnancies or a consequence of a more complex procedure.

\section{Complications}

Studies of early amniocentesis have suggested an excessive risk for talipes equinovarus [19, 28, 29]. Table 1 
shows the rate of amniotic fluid leakage reported in the randomised controlled trials of amniocentesis, as well as the rate of talipes equinovarus in the infants. The earlier amniocentesis was performed, the higher the risk of having amniotic fluid leakage and the higher the rate of talipes. The very high rate of amniotic fluid leakage reported in one study [29] may be due to their definition of leakage. The exact mechanism for the development of talipes remains uncertain, but the relationship to amniotic fluid leakage suggests that decreased amniotic fluid volume is a causal factor [19]. This was also found in a Swedish national registry study of 21,748 women having amniocentesis and 47,854 controls, where the risk of musculoskeletal deformities was increased in cases when amniocentesis had been done before 14 weeks of gestation (OR 1.32, 95\% CI 1.11-1.57) [31].

It is therefore prudent to conclude that amniocentesis should not be performed before 15 weeks.

CVS on the other hand has been linked to limb reduction defects, although the evidence remains conflicting. The first report identified 5 infants with severe limb malformations among 539 pregnancies having undergone CVS before 66 days of gestation [32]. A review of more than 200,000 CVS procedures by the World Health Organization could, however, not substantiate an increase in the incidence of limb reduction defects following CVS [33]. After 10 weeks there was no increased risk of limb reduction defects, while the evidence below 10 weeks of gestation is less substantial [33]. CVS before 10 weeks is best avoided. In exceptional circumstances patients should be informed about a $1 \%$ or higher risk of limb reduction defects.

CVS has been linked to the subsequent development of preeclampsia, while no such association was seen for amniocentesis $[29,34]$. In a case-control study nulliparous women having CVS thus had a more than 4 -fold increased odds of developing preeclampsia [34]. The potential biologic explanation behind this association could be that CVS initiates placental disruption, which may lead to placental dysfunction and preeclampsia. Further studies are needed in this area.

Midtrimester amniocentesis significantly increased the incidence of neonatal respiratory difficulties, i.e. neonatal respiratory distress syndrome and congenital pneumonia with relative risks of 2.1 and 2.5, respectively [8]. This finding was supported by an animal study, in which primates following midtrimester amniocentesis developed structural changes in the lungs not found in control monkeys [35].

Fetal Diagn Ther 2010;27:1-7
It is reassuring that case-control studies with longterm follow-up of infants did not find amniocentesis to be associated with any long-term sequelae in spite of the increased rate of neonatal complications [36,37], nor was this the case for CVS [38].

Accuracy/Reliability of Chromosome Analysis

Tissue culture failure which would require a repeat amniocentesis or CVS is very rare. Chromosome analysis of amniotic fluid samples is highly accurate and the risk of diagnostic error extremely small. This may occur in the presence of maternal cell contamination (0.1-0.2\%) or mosaicism (0.1-0.2\%) [39]. Improved techniques have almost eliminated maternal cell contamination as a source of clinical error.

Mosaicism is detected in approximately $1 \%$ of CVS samples, i.e. ten times more frequently than in amniotic fluid samples. When placental mosaicism is detected, amniocentesis is often performed to assess whether the fetus is affected, which is the case in $10-20 \%$ of these cases.

When mosaicism is limited to the direct preparation, amniocentesis seems to correlate well with fetal genotype. In cases of tissue culture mosaicism, false-positive as well as false-negative results have been found in the amniocentesis sample [40].

The success rate of cytogenetic diagnosis on CVS samples was reported to be $99.7 \%$, with $1.1 \%$ of patients requiring a further diagnostic test to interpret the results [41].

New trends in prenatal diagnosis as a result of technical and laboratory developments have had a great impact on genetic counselling and invasive diagnostic methods. Improvements in laboratory techniques include fluorescence in situ hybridization (FISH) using chromosomespecific DNA probes and amplification of polymorphic chromosome-specific markers by polymerase chain reaction (PCR). The great advantage of these techniques is the possibility to provide karyotyping within $24-48 \mathrm{~h}$, using either amniocytes or chorionic villi. Today most laboratories offer a rapid test (PCR or FISH) to detect trisomy 21,13 and 18, and sex chromosome aneuploidy, as well as tissue culture to provide a full karyotype.

\section{Having Chosen One: When and How to Do It?}

\section{Gestation}

Amniocentesis performed prior to 15 weeks had a significantly higher miscarriage rate than CVS and mid-trimester AC $[18,19,29]$. As well as increasing the miscar- 
riage rate early amniocentesis has been shown to increase the risk of severe talipes equinovarus $[19,28]$. Thus amniocentesis should not be performed before $15+0$ weeks' gestation.

CVS should not be performed before 10 weeks' gestation due to a possible increase in risk of limb reduction defects.

Both procedures could be performed later in pregnan$\mathrm{cy}$, although late CVS procedures have been described as more difficult due to an increased coarseness of the villi with advancing gestation.

\section{Techniques}

Both procedures should be performed under continuous ultrasound monitoring, by 'freehand' technique or using a needle-guide attached to the ultrasound probe.

There was no significant difference in fetal loss rate between two needle insertions and only one insertion during second-trimester amniocentesis [8, 42]. A slight, but statistically significant increase in fetal loss rate was associated with three or more needle insertions $[42,43]$.

A small randomised controlled trial suggested that, although a 20-gauge needle is associated with more discomfort during the procedure, it allowed faster fluid retrieval and was associated with a lower risk of intrauterine bleeding in cases of transplacental needle insertion than a 22-gauge needle [44].

The question of whether a transplacental approach increases the fetal loss rate has not been examined in a randomised setting. In a prospective case-control study of 2,068 women undergoing second-trimester amniocentesis and their 2,068 matched controls, there was no significant difference in fetal loss rate between transplacental and nontransplacental amniocentesis [45].

In a recent Italian single-center study, nearly 35,000 women having amniocentesis were randomised to have antibiotic treatment for three days before the procedure or not [46]. The miscarriage rate within 4 weeks was significantly lower in the intervention group $(0.03 \%)$ than in the control group $(0.28 \%)$, but information about followup until delivery was unfortunately not available.

CVS is a technically more difficult procedure to perform than amniocentesis, and it has been suggested that 100-400 CVS are needed before the learning curve reaches a plateau [47]. CVS may be performed transabdominally or transcervically. Both methods are efficacious, and the choice is in most cases dependent upon physician preference. The transcervical approach was associated with a higher miscarriage rate in randomised trials, but this may be due to lack of operator experience [17]. With appropriate technical equipment an operator with sufficient practical experience may decide on the sampling method in each case. In a UK survey $98 \%$ used the transabdominal approach [48] and in the Northern European countries CVS is almost exclusively performed transabdominally, while in the United States and in Italy both methods are used.

All fetuses should be sampled in multiple pregnancies. It may be discussed whether both fetuses in monochorionic diamniotic twin pregnancies should be sampled due to the very small risk of being dizygotic.

The possibility of discordant results should be discussed with the couple before any testing, including the options available if a disorder is detected. Meticulous care should be taken to clearly map the locations of fetuses and placentas. In twin pregnancies, successful sampling was achieved in $99.3 \%$ of 297 undergoing amniocentesis and in $99.7 \%$ of 163 CVS [49].

Experience has been shown to decrease the procedurerelated fetal loss for amniocentesis [50] as well as for CVS [51]. In a recently published Danish cohort study of more than 60,000 invasive procedures, the miscarriage rate was inversely correlated with the number of procedures performed in a department [21]. For CVS the miscarriage rate was increased in departments performing less than 136 procedures per year compared to departments performing more than 136 procedures per year, while for amniocentesis the miscarriage rate was only increased in those departments performing less than 45 procedures per year. This supports the concept that CVS is a more difficult procedure to master than amniocentesis.

The decreasing number of invasive procedures resulting from the introduction of first trimester risk assessment is a challenge for training as well as for maintaining the expertise of the operators.

\section{Training, Benchmarking, Quality Assurance}

As the number of invasive procedures declines as a result of the introduction of effective screening methods, interest rises concerning the training of new operators. Several training models have been developed to allow handling both the needle and ultrasound probe and their adequate positioning $[51,52]$.

The number of procedures necessary to become an experienced operator has not been specified in any guidelines, but some countries have suggested a minimum of 30 [53] or 100 [54] procedures to maintain expertise.

Operator caseload has been shown to influence amniocentesis sampling efficiency, in that those performing more than 50 procedures over a 36 -month period had a 
higher rate of single-pass success than those performing less than 50 amniocenteses [50].

When assessing performance in relation to invasive procedures, most studies have combined the rate of fetal loss following the procedure from one or more units. Some have used reporting loss within a 1- or 2-week period after the procedure, others pregnancy loss before 24 or 28 weeks. It would facilitate monitoring of these loss rates if an agreed classification system to report pregnancy loss rate after these procedures were available. Nanal et al. [55] suggested calculating pregnancy loss after prenatal invasive procedures, by subtracting the losses in pregnancy with known lethal condition and those occurring more than 2 weeks after the procedure from total pregnancy losses, but this proposal has not gained wide acceptability.

The total rate of fetal loss depends on the case mix of the unit. It would be useful to be able to compare figures from different units adjusting for case mix. Unit-based data are however becoming obsolete, and focus should be on the individual performance of operators [53].

As fetal loss occurs rarely following amniocentesis and CVS, and requires time-consuming follow-up of the whole population, surrogate measures for operator per- formance have been suggested [53]. This could be the proportion of procedures requiring multiple needle insertions, the proportion of procedures with failure to obtain an adequate sample or more readily assessable complications such as 'bloody' tap or amniotic fluid leakage.

These measures of operator experience with target rates should be developed in an international guideline and used for benchmarking.

\section{Conclusion}

The procedure-related miscarriage rate is $0.5-1.0 \%$ for CVS and amniocentesis.

CVS should not be performed before 10 weeks due to the risk of limb reduction defects, amniocentesis not before 15 weeks due to an increased miscarriage rate and more talipes in the newborns. Experienced operators have a higher success rate and a lower complication rate. The decreasing number of prenatal invasive procedures following the introduction of first or second trimester risk assessment calls for quality assurance and monitoring of operators' performance.

\section{References}

1 Jacobson CB, Barter RH: Intrauterine diagnosis and management of genetic defects. Am J Obstet Gynecol 1967;99:796-805.

-2 Boyd PA, DeVigan C, Khoshnood B, Loane M, Garne E, Dolk H, EUROCAT Working Group: Survey of prenatal screening policies in Europe for structural malformations and chromosome anomalies, and their impact on detection and termination rates for neural tube defects and Down's syndrome. BJOG 2008;115:689-696.

$\checkmark 3$ Ekelund CK, Jørgensen FS, Petersen OB, Sundberg K, Tabor A, Danish Fetal Medicine Research Group: Impact of a new national screening policy for Down's syndrome in Denmark; a population based cohort study. BMJ 2008;337:a2547.

4 Nicolaides KH: First-trimester screening for chromosomal abnormalities. Semin Perinatol 2005;29:190-194.

5 Zaragoza E, Akolekar R, Poon LC, Pepes S, Nicolaides KH: Maternal serum placental growth factor at 11-13 weeks in chromosomally abnormal pregnancies. Ultrasound $\mathrm{Ob}$ stet Gynecol 2009;33:382-386.

-6 Evans MI, Goldberg JD, Horenstein J, Wapner RJ, Ayoub MA, Stone J, et al: Selective termination for structural, chromosomal, and Mendelian anomalies: international ex- perience. Am J Obstet Gynecol 1999;181: 893-897.

7 Hoesli IM, Walter-Goebel I, Tercanli S, Holzgreve W: Spontaneous fetal loss rates in a non-selected population. Am J Med Genet 2001;100:106-109.

-8 Tabor A, Madsen M, Obel E, Philip J, Bang J, Norgaard-Pedersen B: Randomised controlled trial of genetic amniocentesis in 4606 low-risk women. Lancet 1986;i:1287-1293.

9 Caughey AB, Hopkins LM, Norton ME: Chorionic villus sampling compared with amniocentesis and the difference in the rate of pregnancy loss. Obstet Gynecol 2006;108: 612-616.

10 Odibo AO, Gray DL, Dicke JM, Stamilio DM, Macones GA, Crane JP: Revisiting the fetal loss rate after second-trimester genetic amniocentesis: a single center's 16-year experience. Obstet Gynecol 2008;111:589595.

11 Tongsong T, Wanapirak C, Sirivatanapa P, Piyamongkol W, Sirichotiyakul S, Yampochai A: Amniocentesis-related fetal loss: a cohort study. Obstet Gynecol 1998;92:6467.

12 Eddleman KA, Malone FD, Sullivan L, Dukes K, Berkowitz RL, Kharbutli Y, Porter TF, Luthy DA, Dugoff L, Craigo SD, Timor-
Tritsch IE, Carr SR, Wolfe HM, D'Alton ME: Pregnancy loss rates after midtrimester amniocentesis. Obstet Gynecol 2006;108:10671072.

13 Mujezinovic F, Alfirevic Z: Procedure-related complications of amniocentesis and chorionic villus sampling. Obstet Gynecol 2007; 110:687-694.

14 Canadian Collaborative CVS-Amniocentesis Clinical Trial Group: Multicentre randomised clinical trial of chorionic villus sampling and amniocentesis. Lancet 1989;i:1-6.

15 Rhoads GG, Jackson LG, Schesselman SA, de la Cruz FF, Desnick RJ, Golbus MS, Ledbetter DH, Lubs HA, Mahoney MJ, Pergament E: The safety and efficacy of chorionic villus sampling for early prenatal diagnosis of cytogenetic abnormalities. N Engl J Med 1989; 320:610-617.

16 MRC Working Party in the Evaluation of Chorion Villus Sampling: Medical Research Council European Trial of chorion villus sampling. Lancet 1991;337:1491-1499.

17 Alfirevic Z, Mujezinovic F, Sundberg K, Brigham S: Amniocentesis and chorionic villus sampling for prenatal diagnosis. Cochrane Database System Rev 2003;issue 3, Art No CD003252. 
18 Nicolaides K, Brizot M de L, Patel F, Snijders $\mathrm{R}$ : Comparison of chorionic villus sampling and amniocentesis for fetal karyotyping at 10-13 weeks' gestation. Lancet 1994;344: 435-439.

19 Canadian Early and Mid-trimester Amniocentesis Trial (CEMAT) Group: Randomised trial to assess safety and fetal outcome of early and midtrimester amniocentesis. Lancet 1998;351:242-247.

20 Muller F, Thibaud D, Poloce F, Gelineau MC, Bernard M, Brochet C, Millet C, Réal JY, Dommergues M: Risk of amniocentesis in women screened positive for Down syndrome with second trimester maternal serum markers. Prenat Diagn 2002;22:10361039.

-21 Tabor A, Vestergaard CHF, Lidegaard Ø: Fetal loss rate after chorionic villus sampling and amniocentesis: an 11-year national registry study. Ultrasound Obstet Gynecol 2009;34:19-24

22 Odibo AO, Dicke JM, Gray DL, Oberle B, Stamilio DM, Macones GA, Crane JP: Evaluating the rate and risk factors for fetal loss after chorionic villus sampling. Obstet Gynecol 2008; 112:813-819.

-23 Sperling L, Kiil C, Larsen LU, Qvist I, Schwartz M, Jørgensen C, Skajaa K, Bang J, Tabor A: Naturally conceived twins with monochorionic placentation have the highest risk of fetal loss. Ultrasound Obstet Gynecol 2006;28:644-652.

-24 Cahill AG, Macones GA, Stamilio DM, Dicke JM, Crane JP, Odibo AO: Pregnancy loss rate after mid-trimester amniocentesis in twin pregnancies. Am J Obstet Gynecol 2009;200: 257.e1-257.e6.

25 Yukobowich E, Anteby EY, Cohen SM, Lavy Y, Granat M, Yagel S: Risk of fetal loss in twin pregnancies undergoing second trimester amniocentesis. Obstet Gynecol 2001;98:231234.

26 Jenkins TM, Wapner RJ: The challenge of prenatal diagnosis in twin pregnancies. Curr Opin Obstet Gynecol 2000;12:87-92.

-27 Millaire M, Bujold E, Morency A-M, Gauthier RJ: Mid-trimester genetic amniocentesis in twin pregnancy and the risk of fetal loss. J Obstet Gynaecol Can 2006;28:512-518.

28 Sundberg K, Bang J, Smidt-Jensen S, Brocks V, Lundsteen C, Parner J, Philip J: Randomised study of the risk of fetal loss related to early amniocentesis versus chorionic villus sampling. Lancet 1997;350:697-703.

29 Philip J, Silver RK, Wilson RD, Thom EA, Zachary JM, Mohide P, Mahoney MJ, Simpson JL, Platt LD, Pergament E, Hershey D, Filkins K, Johnson A, Shulman LP, Bang J, MacGregor S, Smith JR, Shaw D, Wapner RJ, Jackson LG: Late first-trimester invasive prenatal diagnosis: results of an international randomized trial. Obstet Gynecol 2004;103: $1164-1173$.
30 Smidt-Jensen S, Permin M, Philip J, Lundsteen C, Zachary JM, Fowler SE, Grüning K: Randomised comparison of amniocentesis and transabdominal and transcervical chorionic villus sampling. Lancet 1992;340: 1237-1244.

31 Cederholm M, Haglund B, Axelsson O: Infant morbidity following amniocentesis and chorionic villus sampling for prenatal karyotyping. BJOG 2005;112:394-402.

32 Firth HV, Boyd PA, Chamberlain P: Severe limb abnormalities after chorion villus sampling at 56-66 days of gestation. Lancet 1991; 337:762-763.

33 Froster UG, Jackson L: Limb defects and chorionic villus sampling: results from an international registry, 1992-1994. Lancet 1996;347:489-494.

34 Grobman WA, Auger M, Shulman LP, Elias $S$ : The association between chorionic villus sampling and preeclampsia. Prenat Diagn 2009;29:800-803.

35 Hislop A, Fairweather DVI: Amniocentesis and lung growth: an animal experiment with clinical implications. Lancet 1982;ii:12711272

36 Baird PA, Yee IM, Sadovnik AD: Populationbased study of long-term outcomes after amniocentesis. Lancet 1994;344:1134-1136.

37 Finegan JA, Sitarenios G, Bolan PL, Sarabura $\mathrm{AD}$ : Children whose mothers had second trimester amniocentesis: follow up at school age. Br J Obstet Gynaecol 1996;103:214-218.

38 Schaap AHP, van der Pol HG, Boer K, Leschot NJ, Wolf H: Long-term follow-up of infants after transcervical chorionic villus sampling and after amniocentesis to compare congenital abnormalities and health status. Prenat Diagn 2002;22:598-604.

39 Gosden C, Tabor A, Leck I, Grant A, Alfirevic Z, Wald N: Amniocentesis and chorionic villus sampling; in Wald N, Leck I (eds): Antenatal and Neonatal Screening. London, Oxford University Press, 2000, pp 470-517.

40 Eisenberg B, Wapner RJ: Clinical procedures in prenatal diagnosis. Clin Obstet Gynecol 2002;16:611-627.

41 Ledbetter DH, Martin AO, Verlinsky Y, Pergament E, Jackson L, Yang-Feng T, Schonberg SA, Gilbert F, Zachary JM, Barr M: Cytogenetic results of chorionic villus sampling: high success rate and diagnostic accuracy in the United States collaborative study. Am J Obstet Gynecol 1990;162:495-501.

42 NICHD National Registry for amniocentesis study group: midtrimester amniocentesis for prenatal diagnosis: safety and accuracy. JAMA 1976;236:1471-1476.
43 Marthin T, Liedgren S, Hammar M: Transplacental needle passage and other risk-factors associated with second trimester amniocentesis. Acta Obstet Gynecol Scand 1997;76:728-732.

44 Athanasiadis AP, Pantazis K, Goulis DG, Vaitsi V, Assimakopoulos E, Tzevelekis F, Tsalikis T, Bontis JN: Comparison between $20 \mathrm{G}$ and $22 \mathrm{G}$ needle for second trimester amniocentesis in terms of technical aspects and short-term complications. Prenat Diagn 2009;29:761-765.

45 Müngen E, Tütüncü L, Muhcu M, Yergök YZ: Pregnancy outcome following secondtrimester amniocentesis: a case-control study. Am J Perinatology 2006;23:25-30.

46 Giorlandino C, Cignini P, Cini M, Brizzi C, Carcioppolo O, Milite V, Coco C, Gentili P, Mangiafico L, Mesoraca A, Bizzoco D, Gabrielli I, Mobili L: Antibiotic prophylaxis before second-trimester genetic amniocentesis (APGA): a single-centre open randomised controlled trial. Prenat Diagn 2009;29:6-12.

47 Nizard J, Dumez M, Ville Y: Teaching ultrasound-guided invasive procedures in fetal medicine: learning curves with and without an electronic guidance system. Ultrasound Obstet Gynecol 2002;19:274-277.

48 Carlin AJ, Alfirevic Z: Techniques for chorionic villus sampling and amniocentesis: a survey of practice in specialist UK centres. Prenat Diagn 2008;28:914-919.

49 van den Berg C, Braat AP, Van Opstal D, Halley DJ, Kleijer WJ, den Hollander NS, Brandenburg H, Pijpers L, Los FJ: Amniocentesis or chorionic villus sampling in multiple gestations? Experience with 500 cases. Prenat Diagn 1999; 19:234-244.

- 50 Silver RK, Russell TL, Kambich MP, Leeth EA, MacGregor SN, Sholl JS: Midtrimester amniocentesis: influence of operator caseload on sampling efficiency. J Reprod Med 1998;43:191-195

-51 Wijnberger LDE, Schouw YT van der, Christiaens GCML: Learning in medicine: chorionic villus sampling. Prenat Diagn 2000;20: 241-246.

52 Ville Y, Cooper M, Revel A, Frydman R, Nicolaides KH: Development of a training model for ultrasound-guided invasive procedures in fetal medicine. Ultrasound Obstet Gynecol 1995;5:180-183.

53 Alfirevic Z: Who should be allowed to perform amniocentesis and chorionic villus sampling? Ultrasound Obstet Gynecol 2009; 34:12-13.

54 The Danish National Board of Health: Report from a working commission 'Prenatal diagnosis and risk assessment' http://www. sst.dk/upload/fosterdiagnostik1_001.pdf. Copenhagen, 2003.

55 Nanal R, Kyle P, Soothhill PW: A classification of pregnancy losses after invasive prenatal diagnostic procedures: an approach to allow comparison of units with a different case mix. Prenat Diagn 2003;23:488-492. 